\title{
1 Individual plasticity drives boldness senescence in a territorial butterfly
}

3 Running title: Boldness senescence in a butterfly

4

$5 \quad$ Aurélien Kaiser ${ }^{1}$, Manon Eymard ${ }^{1}$, Thomas Merckx ${ }^{1,2}$ \& Hans Van Dyck ${ }^{1}$

$7 \quad{ }^{1}$ Behavioural Ecology \& Conservation Group, Earth \& Life Institute, UCLouvain, Louvain-la8 Neuve, Belgium

${ }^{2}$ Department of Ecology and Genetics, University of Oulu, Oulu, Finland

ORCID Aurélien Kaiser: 0000-0001-7552-8748

ORCID Thomas Merckx: 0000-0002-6195-3302

ORCID Hans Van Dyck: 0000-0002-2013-6824

Corresponding author: Aurélien Kaiser; E-mail: kaiser.aurelien@gmail.com; Tel: +32 (0) 10 This is the peer reviewed version of the following article: Kaiser, A, Eymard, M, Merckx, T, Van Dyck, H. Individual plasticity drives boldness senescence in a territorial butterfly. Ethology. 2020; 126: 10611068, which has been published in final form at https://doi.org/10.1111/eth.13084. This article may be used for non-commercial purposes in accordance with Wiley Terms and Conditions for Self-Archiving." 


\section{Acknowledgements}

We thank two anonymous reviewers for their constructive comments. AK was supported by an Aspirant grant from the Belgian Fund of Scientific Research F.S.R.-FNRS. The research was supported by PDR grant FNRS PDR T.0188.14 and an ARC research grant of Fédération Wallonie-Bruxelles and UCLouvain (ARC-grant 17/22-086) to HVD. This is publication number BRC 364 of the Biodiversity Research Centre (ELI/ELIB, UCLouvain).

\section{Abstract}

Most behavioural traits show plastic responses to changes in internal or external conditions. Similarly, animal personality is not necessarily fixed during an individual's lifetime, leading to age-related changes. Both individual plasticity (i.e. within-individual effect) and non-random selective (dis)appearance of behavioural types (i.e. between-individual effect) may contribute to age-related changes observed at the population level. Here, we investigated how boldness changes with age in a woodland population of the Speckled wood butterfly (Pararge aegeria L.) using a capture-mark-recapture approach. We used wing wear as an index for age and we show that fresh individuals are bolder than worn individuals. Using the subsample of recaptured butterflies, we found that this pattern is most likely driven by individual plasticity. Our design also allowed us to explore some aspects of the species' spatial ecology and how it relates to personality. We found no relationship between boldness and net displacement between successive captures, a finding which we discuss within a movement ecology framework.

\section{Keywords}

Animal personality - Behavioural syndrome - Lepidoptera - Movement ecology - Pararge aegeria - Routine movements - Thermal ecology 


\section{Introduction}

Phenotypic plasticity is an important trait that enables organisms to cope with changing environmental conditions. Virtually all phenotypic traits can show plastic responses at some point, either triggered by external or internal cues. In this context, ageing can be a major driver of within-individual changes. For example, reproductive senescence, the age-related decline in reproductive output, is widely documented in wild animals (Lemaittre and Gaillard 2017) and is thought to occur mainly as a consequence of within-individual changes (Nussey et al. 2008). Yet, between-individual changes such as selective (dis-)appearance of certain phenotypes may also explain trait differences between age classes. At the population level, reduced reproductive performance in older individuals may well be due to good reproducers trading off reproductive output with lifespan, and hence dying earlier than poor reproducers (i.e. selective disappearance). Alternatively, poor reproducers may be excluded from reproducing at a young age by more competitive individuals and they may gain access to reproduction only late in life (i.e. selective appearance) (van de Pol and Verhulst 2006). Obviously, a wide array of morphological, physiological and behavioural traits may differ between age classes. Consequently, a proper evaluation of within- versus between-individual changes is needed to fully understand such dynamics.

The study of personalities has gained ground within behavioural ecology (David and Dall 2016). While in humans there is a long tradition of quantifying personality traits, only during the last twenty years or so a lot of evidence has been accumulating on conceptually similar variation in non-human animals (Gosling 2008). Personality refers to inter-individual, intraspecific behavioural variation that is stable over time and in different contexts (Stamps and Groothuis 2010). Nonetheless, the concept of personality does not imply that personality traits are necessarily fixed within an individual's lifetime. Just as with other behaviours, individuals may display plastic adjustments to personality traits. Recent studies have shown that personality 
changes with age (e.g. Humphries et al. 2015; Favati et al. 2016; Polverino et al. 2016; Stanley et al. 2017). Although only few studies have tried to tease apart within- and between-individual changes, age-related changes in personality traits appear so far to be mainly caused by withinindividual changes (i.e. individual plasticity) (e.g. Class and Brommer 2016; Fisher et al. 2018).

The Speckled wood butterfly (Pararge aegeria) is a long-established study system in behavioural ecology. Particularly the mate location behaviour in males has attracted much attention since the game theory-inspired pioneer field study by Nick Davies (Davies 1978). Males try to monopolize a sunlit patch on the forest floor as a rendezvous site for receptive females, which they aggressively defend against other males (reviewed in Van Dyck 2003). More recently, consistent inter-individual variation in behavioural traits has been documented in P. aegeria, providing evidence for personality traits in this butterfly (Ducatez et al. 2014; Kaiser et al. 2018). Here, within the same species, we tested the repeatability of a boldness measure under variable field conditions and we investigated age-related changes in this personality trait in a wild woodland population. In a recent study, we reported on boldness senescence in laboratory-reared Speckled woods (Kaiser et al. 2019a). While betweenindividual changes were an unlikely cause of age-related decline in boldness in this F1 captivereared population, different mechanisms may be at work in natural populations. Indeed, maintaining animals in laboratories often involves providing ad-libitum food and ensuring the absence of predators and pathogens, but such conditions may disrupt the relationship between behaviour and survival (Moiron et al. 2020). In this context, typically harsher natural conditions provide useful set-ups to investigate the role of between-individual patterns. Because bold individuals are supposed to take more risks when exposed to threats (Réale et al. 2007), one may expect bold phenotypes to be removed first form a population (i.e. selective disappearance of bold types). However, since the boldness test we developed mimics a butterfly being stuck in, for example, a spider web or a bird's beak (see below), we can actually expect the opposite 
pattern as bold individuals may be able to escape their predators more easily by moving more under stressful conditions. Whatever their direction, such between-individual changes may be reinforced (or instead, counteracted) by within-individual changes, as both mechanisms may play a role in shaping age-related changes in boldness in natural populations (van de Pol and Verhulst 2006). As such, a proper evaluation of the underlying processes is required.

Our capture-mark-recapture study also enabled us to test hypotheses on species-specific thermal ecology and to evaluate whether boldness relates to space use in male Speckled woods. Recently, Spiegel et al. (2017) proposed a framework that links personality traits with some aspects of spatial dynamics in animal populations. While several studies have shown that dispersal is often non-random and biased towards some behavioural types (i.e. personalitydependent dispersal - Cote et al. 2010), few studies have investigated the co-variation between personality traits and aspects of daily space use such as home range size (Spiegel et al. 2017). As an attempt to investigate this in an invertebrate species, we used the net displacement between successive captures as a proxy for space use. While some personality traits, such as activity and exploration, are inherently linked to movements, the relationship between boldness and daily movements is less straightforward. Yet, we expect such a co-variation to arise because shy individuals are expected to take less risks and to more strongly avoid risky environments. We thus expect shy butterflies to settle with high fidelity on territories that they perceive as safe, while we expect bolder individuals to move longer distances between successive captures, indicating larger home ranges.

\section{Material and methods}

Study species 
The Speckled wood ( $P$. aegeria L.) is a satyrine butterfly occurring principally in woodland and along woodland edges across its European range (Settele et al. 2008). In Belgium and The Netherlands, it is a very common and widespread species (Van Dyck et al. 2009). The species has a monandrous mating system (Svärd 1985) and males typically emerge before females (i.e. protandry - Gotthard et al. 1994). Under woodland habitat conditions males locate females by either territorial perching or by patrolling (Van Dyck et al. 1997).

\section{Study site}

Our study was conducted in a 231 ha woodland, called 'Bois de Lauzelle'. This mixed woodland is locally dominated by oak trees (Quercus robur). It is owned by the UCLouvain university and situated near the university campus. Data were collected in the summer of 2018, from July to September, within the period corresponding to the cohort of directly developed summer generation adults (i.e. development without a larval or pupal diapause - Wiklund et al. 1983). A map of the study area showing the location of all capture events is shown in Figure S1.

Personality trait, temperature, body size and net displacement

We collected data on Speckled wood males adopting a territorial perching mate location strategy. If a male was spotted during the walking route across the study area, its behaviour was observed to confirm the status of being a territorial male on a sunlit patch at the forest floor (see Van Dyck et al. 1997). Next, the male was captured with a butterfly net and relative adult age was estimated based on the level of wing wear. We used a four-level scale $(1=$ freshly emerged adult, to $4=$ heavily damaged wings, i.e. lost wing scales and a significant loss of wing fragments) (cf. Kemp and Alcock 2003; Takeuchi 2006).

Then, the butterfly was gently placed with closed wings in a semi-transparent glassine envelope $(63 \times 97 \mathrm{~mm})$ and we counted the number of movements the butterfly made either with the 
head, the wings or the legs during one minute under these stressful conditions. For further details about this boldness test and its significance, we refer to our previous work (Kaiser et al. 2018, 2019a, b). After the test, the butterfly was marked by writing a unique number on the left ventral hind wing and we measured body temperature by making contact at the level of the thorax with an infrared thermometer (IBP TS 402). We took three measures within a minute and calculated the average value. Simultaneously, ambient temperature was also measured in the shade close to the sunlit patch (HOBO Pendant Temperature/Light 64K data logger). Before we released the butterfly, we measured the right forewing length from the wing base (i.e. close to the thorax) to the wing tip with a digital calliper (precision: $\pm 0.1 \mathrm{~mm}$ ). Wing length was measured three times and we calculated the average as a measure of body size for each individual male. We also recorded capture coordinates (World Geodetic System - WGS84) using the free smartphone app "My GPS Coordinates". Coordinates were written down when the spatial accuracy provided by the app was at least $15 \mathrm{~m}$. A single observer (ME) conducted all behavioural observations and carried out all measurements.

For recaptured individuals, we also calculated the net displacement (i.e. Euclidean distance) between the first and the second capture site, based on capture coordinates imported into QGIS (version 3.6). As very few individuals $(\mathrm{N}=4)$ were captured more than two times, we calculated the net displacement between the first and second capture only.

\section{Statistical analysis}

All statistical analyses were performed with R 3.5.1 (R Core Team 2020) and all continuous variables were scaled prior to analysis. We analysed the relationship between thorax temperature and ambient temperature using a linear mixed model (lme4 package). Thorax temperature was the response variable and ambient temperature and forewing length (used as a proxy for body size) were the explanatory variables. Because some individuals were measured several times, we included individual ID as a random effect (i.e. random intercept). We also 
included date as a random effect (random intercept). For the analysis of thorax temperature, we used the complete dataset $(\mathrm{N}$ observations $=212 ; \mathrm{N}$ individuals $=183)$. Boldness was analysed with a generalized linear model, with a Poisson error structure and log link function. We fitted two models. The first model included wing wear (treated as a factor), thorax temperature and forewing length as explanatory variables. Again, we included individual ID and date as random effects in the model. This first model included all behavioural observations (i.e. complete dataset, see above). Based on this model, we estimated boldness repeatability (using the rptR package).

Because we found that boldness decreased with wing wear (i.e. a proxy for age) at the population level and we aimed to unravel whether this was due to within- or between-individual effects, we fitted a second model for boldness using a within-individual centring approach (see van de Pol and Wright 2009). The general idea is to decompose age effects into two variables that would reflect within- and between-individual changes. Because the precise age of wildcaught individuals could not be known with precision, we used the number of days since the first capture (to which we applied within-individual centring) as a proxy for within-individual effects. We used individual's maximum wing wear values as a proxy for between-individual effects (treated as a factor) because we aimed at testing the effect of selective disappearance (van de Pol and Verhulst 2006). The model again included thorax temperature and forewing length as explanatory variables and individual ID and date as random effects. The dataset used for this model only contained individuals which were assessed multiple times for boldness ( $\mathrm{N}$ observations $=54 ; \mathrm{N}$ individuals $=25)$.

Net displacement (in meters) between the first and second captures was log-transformed prior to analysis to achieve normality of the residuals. Using data collected from recaptured males $(\mathrm{N}=25)$, we fitted a linear model with forewing length and the number of days elapsed between the two captures as explanatory variables. 
Finally, we assessed the correlation between boldness and net displacement in recaptured males using a bivariate Bayesian model (MCMCglmm package). The model contained boldness and net displacement (log-transformed) as response variables. Similar to the univariate models presented above, we included trait-specific fixed effects: wing wear, thorax temperature and forewing length for boldness; forewing length and the number of days elapsed between the two captures for net displacement. Random effects included individual ID and date. Boldness and net displacement were fitted with a Poisson and a Gaussian error structure, respectively. We used a non-informative prior, with 300,000 iterations, from which we discarded the first 30,000 (burn-in), while using a thinning interval of 100. These model specifications resulted in low autocorrelation and we performed three runs to confirm the robustness of the outputs. Then, we computed the between-individual correlation between boldness and net displacement. The correlation was considered significant when the $95 \%$ credible interval did not overlap with zero.

\section{Results}

A total of 183 territorial males were captured at least once. Among those, 158 were captured once, 21 twice and four individuals were captured three times (i.e. overall recapture rate of 13.7\%). Their thorax temperatures varied between 24.5 and $35.1^{\circ} \mathrm{C}$, with $74.5 \%$ of the values in the 28 to $32^{\circ} \mathrm{C}$ range. Thorax temperature increased with ambient temperature $\left(\mathrm{F}_{1,165.3}=\right.$ 187.54, $P<0.001$; Fig. 1), being on average $3.6 \pm 1.4^{\circ} \mathrm{C}$ (mean \pm SD) above ambient temperatures, and was not related to body size $\left(\mathrm{F}_{1,165.7}=0.0001, P=0.99\right)$.

During the one-minute test the boldness score varied considerably among males, from no movement at all in $45.8 \%$ (97/212) of the assessments to 32 movements (Fig. S2). Boldness shows a significant repeatability of 0.65 (95\% confidence interval: $0.27-0.88)$. Overall, boldness scores increased with increasing thorax temperature $\left(\chi^{2}{ }_{1}=5.15 ; P=0.023\right)$ and older 
males, as measured by their level of wing wear, had lower boldness scores than young males $\left(\chi^{2} 3=13.39 ; P=0.004 ;\right.$ Fig. 2). Pairwise comparisons (Tukey post-hoc test) showed that young individuals had on average higher boldness scores than worn individuals (wing wear 1 versus 3: $\mathrm{P}=0.004$; wing wear 1 versus $4: \mathrm{P}=0.024$; wing wear 2 versus $3: \mathrm{P}=0.010$; $\mathrm{P}$-values obtained after applying Benjamini \& Hochberg adjustment for multiple testing) (Fig. 2). Boldness was independent of body size $\left(\chi^{2}{ }_{1}=1.19 ; P=0.28\right)$.

Using the subset of individuals that were assessed multiple times for boldness, we explored whether the observed age-related decline in mean boldness occurred because of individual plasticity versus selective disappearance. Maximum wing wear (used as a proxy for betweenindividual effects) was unrelated to boldness $\left(\chi^{2} 3=4.53 ; P=0.21\right)$, while boldness tended to decrease with time since the first capture (after applying within-individual centring - used as a proxy for within-individual effects) $\left(\chi^{2}{ }_{1}=2.78 ; P=0.095\right)$ (Fig. 3).

The distance moved between the first and second capture varied between 2 and $445 \mathrm{~m}$. However, more than half of the recaptures (14/25) occurred within $50 \mathrm{~m}$ (Fig. S3). Net displacement was neither related to forewing length $\left(\mathrm{F}_{1,22}=0.29, P=0.59\right)$, nor to the number of days elapsed between both captures $\left(\mathrm{F}_{1,22}=1.89, P=0.18\right)$. We found no significant correlation between boldness and net displacement in recaptured males (between-individual correlation: -0.09 - credible interval: $-0.59 ; 0.42$ ).

\section{Discussion}

Using a capture-recapture design, we assessed variation in boldness in a woodland population of the Speckled wood butterfly. Our field study showed that, at the population level, boldness declined with increasing age, and we show that this is probably due to within- rather than between-individual changes. We also investigated whether boldness correlated with net 
displacement between captures as a simple measure of space use, but we did not find evidence for such a relationship. In the following sections, we will discuss these results in the light of the ecology of the study species and integrate our current findings with the existing knowledge on butterfly personality.

\section{Body temperature}

While the age dynamic of boldness and its co-variation with space use were the primary focus of our study, our experimental design also allowed us to study some aspects of the thermal ecology of the Speckled wood in woodland habitat and to compare our results and methods to previously published works on this species. Thoracic temperature scaled with ambient temperature and about $75 \%$ of the butterflies had a thoracic temperature in the range of 28 to $32^{\circ} \mathrm{C}$. While our results are overall similar to those obtained by Van Dyck \& Matthysen (1998), some slight discrepancies can be pointed out that probably relate to methodological differences. For instance, the latter study reported slightly higher (i.e. $\left.+2^{\circ} \mathrm{C}\right)$ thoracic temperatures, which may be due to the use of a thermocouple sensor inserted inside the thorax while we measured surface temperature. In the butterfly Heteronympha merope, internal thorax temperature measured with such a probe was indeed $1.3^{\circ} \mathrm{C}$ higher than surface temperature (Nève and Hall 2016). Also, Van Dyck \& Matthysen (1998) measured internal temperature shortly after capture (within 5 seconds) while in our study at least 1 minute (i.e. the duration of the boldness assessment and butterfly marking) systematically elapsed before we recorded thoracic temperature. Accounting for those methodological aspects may well explain the difference between both studies.

\section{Age-related change in boldness: within- versus between-individual changes}

Here, we tested for personality under field conditions in the Speckled wood. By far most personality studies make use of laboratory settings, often with reared individuals as we did 
previously too (Kaiser et al. 2019a, b). It is therefore interesting to underscore that despite the increased environmental variation under woodland conditions (e.g. in temperature, humidity level or solar radiation), we were still able to show a significant repeatability for boldness. While our simple test proved to be useful to assess boldness under controlled, laboratory conditions, our current results show that the envelope test can also be used to quantify boldness variation in wild populations.

Using wing wear as a proxy for age, we detected an age-related decline in boldness at the population level. Based on the subset of individuals that were captured and assessed for boldness multiple times, we aimed to unravel the underlying mechanisms responsible for the observed decline in boldness with age. Although our ability to discriminate within- and between-individual changes was ultimately limited by the relatively low recapture rate, our results suggest that individual plasticity (i.e. within-individual changes) was the main cause of boldness senescence in the study population. Moiron et al. (2020) found that shy individuals generally have a reduced lifespan under natural conditions (i.e. wild populations as opposed to laboratory conditions). Thus, one could expect selective disappearance to play an important role in shaping age-related changes in personality traits at the population level, but we found no evidence for such an effect in our study. Rather, we found a trend for within-individual changes in boldness. Interestingly, a similar decline of boldness at the population level occurred in laboratory-reared Speckled wood butterflies (Kaiser et al. 2019a) which also appeared to be driven by within-individual changes as mortality was typically very low in the laboratory and selective disappearance of bold types was unlikely to cause the observed pattern. This strongly suggests that individual plasticity is the underlying mechanism explaining the age-related decline in the mean level of boldness, and this in both wild and laboratory populations of the Speckled wood butterfly. 
Individual plasticity of personality traits as individuals get older has been reported a few times, but the direction of those changes appears to vary among species. For example, handling aggression decreased with age in a wild population of Great tits (Parus major) (Class and Brommer 2016), while activity and the tendency to leave a tube both increased as individual Field crickets (Gryllus campestris) get older (Fisher et al. 2015, 2018). The direction of the change probably depends on the trait itself, how it relates to fitness components and the proximate mechanism underlying this change. Identifying the proximate cause of the decline in boldness observed here was beyond the scope of this study. We can only speculate about potential proximate mechanisms, which for instance include age-related decline in brain size (Pasquet et al. 2018) and energy depletion, both of which could negatively affect the expression of personality traits. This now warrants further research.

\section{Within-site movements and boldness}

In his pioneer work on the Speckled wood butterfly, Davies (1978) noted that males tend to be very sedentary, with as much as $90 \%$ of the marked individuals spending their entire life within $50 \mathrm{~m}$ of the point of first capture. Similarly, Bergerot et al. (2012) found that recapture probability of Speckled woods was highest at $25 \mathrm{~m}$ from the initial capture location. Males in our study population display a high site fidelity too, with $56 \%$ of the recaptures occurring within $50 \mathrm{~m}$, and $80 \%$ within $100 \mathrm{~m}$.

Many personality traits are (in-) directly linked to information gathering and spatial processes, and thus they may be expected to influence daily movements occurring at relatively small spatial scales (Spiegel et al. 2017). Recent empirical studies confirmed that personality indeed plays a role in shaping such movements (e.g. Minderman et al. 2010; Spiegel et al. 2015; Villegas-Ríos et al. 2018; Schirmer et al. 2019). Yet, our current knowledge on animal personality, and how it relates to other biological processes, remains heavily biased towards vertebrates (Kralj-Fišer and Schuett 2014). Here, as a first attempt to explore the relationship 
between a personality trait and space use in a territorial butterfly species, we investigated under natural conditions whether boldness related to net displacement in the Speckled wood. However, neither boldness nor forewing length affected local movements within a sunlit patch or between sunlit patches. Thus, net displacement appears to be independent of personality and flight morphology in our study. Perhaps this pattern is not surprising as we focused on territorial males whose mate-location strategy mainly involves routine movements biased towards their territories. Here we should stress that there are clear differences between routine movements and large-scale movements such as dispersal. The former include movements associated with daily activities like foraging and mate-location (Van Dyck and Baguette 2005), while the latter involve between-population movements underpinned by a decision to leave a habitat patch for another (Stevens et al. 2010, 2014). Large-scale movements associated with dispersal likely require a special set of behavioural, physiological and morphological traits, integrated within dispersal syndromes (Stevens et al. 2014). In butterflies, dispersal syndromes typically include long wings (Stevens et al. 2012) and strong flight performance (as measured under stressful conditions; Legrand et al. 2015). Routine movements, however, may not require such a special design (Van Dyck and Baguette 2005), while we can expect the spatial distribution and dynamics of resources to play an important role in shaping daily movements. This has been shown, for example, in two related satyrine butterfly species, where local flight activity at both the individual and species level was not linked to forewing length - and hence dispersal capacity - but where local occurrence was closely linked to the presence of habitat resources (Merckx and Van Dyck 2002).

Yet, we acknowledge that our study does not provide final, clear-cut evidence for the absence of a personality/space use relationship in the Speckled wood. Here, we considered only one aspect of local space use that relates to territoriality. It would now be interesting to monitor a set of males more closely and more frequently than we did in our current study to obtain precise 
estimates of their realized home range. It could well be that bold perchers are able to hold larger territories and to cover larger home ranges than perchers that are less bold. Additionally, we only considered territorial males, but the mate-locating behaviour system in the Speckled wood butterfly involves both territorial and patrolling males within the same population (Van Dyck 2003 and references therein). Both patrollers and females (i.e. the dispersive sex in P. aegeria - Hill et al. 1999) are by nature less territorial and even their routine movements are likely to occur at wider spatial scales compared to territorial males. Consequently, for females and patrolling males we do expect a relationship between personality and space use. As such, we hope our work will inspire and stimulate further research on the interplay between personality traits and spatial ecology in the Speckled wood, and more generally in other invertebrate taxa. Invertebrates play important roles in ecosystems and understanding how personality shapes their daily movements relative to other factors is therefore important. In this regard, the further miniaturization of (GPS) tracking devices (see for example Woodgate et al. 2016) will benefit this field of research. Indeed, obtaining long-term data on individual animal movements is currently challenging, but of prime importance to accurately explore personality and space use relationships (Spiegel et al. 2017).

\section{References}

Bergerot B, Merckx T, Van Dyck H, Baguette M (2012) Habitat fragmentation impacts mobility in a common and widespread woodland butterfly: do sexes respond differently? BMC Ecol 12:5. doi: $10.1186 / 1472-6785-12-5$

Class B, Brommer JE (2016) Senescence of personality in a wild bird. Behav Ecol Sociobiol 70:733-744. doi: 10.1007/s00265-016-2096-0

Cote J, Clobert J, Brodin T, et al (2010) Personality-dependent dispersal: characterization, 
ontogeny and consequences for spatially structured populations. Philos Trans R Soc Lond B Biol Sci 365:4065-76. doi: 10.1098/rstb.2010.0176

David M, Dall SRX (2016) Unravelling the philosophies underlying 'Animal Personality' studies: a brief re-appraisal of the field. Ethology 122:1-9. doi: 10.1111/eth.12445

Davies NB (1978) Territorial defence in the speckled wood butterfly (Pararge aegeria): The resident always wins. Anim Behav 26:138-147. doi: 10.1016/0003-3472(78)90013-1

Ducatez S, Humeau A, Congretel M, et al (2014) Butterfly species differing in mobility show different structures of dispersal-related syndromes in the same fragmented landscape. Ecography (Cop) 37:378-389. doi: 10.1111/j.1600-0587.2013.00365.x

Favati A, Zidar J, Thorpe H, et al (2016) The ontogeny of personality traits in the red junglefowl, Gallus gallus. Behav Ecol 27:484-493. doi: 10.1093/beheco/arv177

Fisher DN, David M, Rodríguez-Muñoz R, Tregenza T (2018) Lifespan and age, but not residual reproductive value or condition, are related to behaviour in wild field crickets. Ethology 124:338-346. doi: 10.1111/eth.12735

Fisher DN, David M, Tregenza T, Rodríguez-Muñoz R (2015) Dynamics of among-individual behavioral variation over adult lifespan in a wild insect. Behav Ecol 26:975-985. doi: 10.1093/beheco/arv048

Gosling SD (2008) Personality in non-human animals. Soc Personal Psychol Compass 2:9851001. doi: 10.1111/j.1751-9004.2008.00087.x

Gotthard K, Nylin S, Wiklund C (1994) Adaptive variation in growth rate: life history costs and consequences in the speckled wood butterfly, Pararge aegeria. Oecologia 99:281-289. doi: 10.1007/BF00627740

Hill JK, Thomas CD, Blakeley DS (1999) Evolution of flight morphology in a butterfly that 
has recently expanded its geographic range. Oecologia 121:165-170. doi: $10.1007 / \mathrm{s} 004420050918$

Humphries MM, McAdam AG, Boutin S, Kelley AD (2015) Changes in wild red squirrel personality across ontogeny: activity and aggression regress towards the mean. Behaviour 152:1291-1306. doi: 10.1163/1568539X-00003279

Kaiser A, Merckx T, Van Dyck H (2018) Urbanisation and sex affect the consistency of butterfly personality across metamorphosis. Behav Ecol Sociobiol 72:188. doi: $10.1007 / \mathrm{s} 00265-018-2616-1$

Kaiser A, Merckx T, Van Dyck H (2019a) Personality traits influence contest outcome, and vice versa, in a territorial butterfly. Sci Rep 9:2778. doi: 10.1038/s41598-019-39155-9

Kaiser A, Merckx T, Van Dyck H (2019b) Behavioural repeatability is affected by early developmental conditions in a butterfly. Anim Behav 157:219-226. doi: 10.1016/j.anbehav.2019.08.006

Kemp DJ, Alcock J (2003) Lifetime resource utilization, flight physiology, and the evolution of contest competition in territorial insects. Am Nat 162:290-301. doi: 10.1086/376890

Kralj-Fišer S, Schuett W (2014) Studying personality variation in invertebrates: why bother? Anim Behav 91:41-52. doi: 10.1016/j.anbehav.2014.02.016

Legrand D, Trochet A, Moulherat S, et al (2015) Ranking the ecological causes of dispersal in a butterfly. Ecography (Cop) 38:822-831. doi: 10.1111/ecog.01283

Lemaître J-F, Gaillard J-M (2017) Reproductive senescence: new perspectives in the wild. Biol Rev 92:2182-2199. doi: 10.1111/brv.12328

Merckx T, Van Dyck H (2002) Interrelations among habitat use, behavior, and flight-related morphology in two cooccurring satyrine butterflies, Maniola jurtina and Pyronia tithonus. 
409

410

Minderman J, Reid JM, Hughes M, et al (2010) Novel environment exploration and home range size in starlings Sturnus vulgaris. Behav Ecol 21:1321-1329. doi: 10.1093/beheco/arq151

Moiron M, Laskowski KL, Niemelä PT (2020) Individual differences in behaviour explain variation in survival: a meta-analysis. Ecol Lett 23:399-408. doi: 10.1111/ele.13438

Nève G, Hall C (2016) Variation of thorax flight temperature among twenty Australian butterflies (Lepidoptera: Papilionidae, Nymphalidae, Pieridae, Hesperiidae, Lycaenidae). Eur J Entomol 113:571-578. doi: 10.14411/eje.2016.077

Nussey DH, Coulson T, Festa-Bianchet M, Gaillard J-M (2008) Measuring senescence in wild animal populations: towards a longitudinal approach. Funct Ecol 22:393-406. doi: 10.1111/j.1365-2435.2008.01408.x

Pasquet A, Toscani C, Anotaux M (2018) Influence of aging on brain and web characteristics of an orb web spider. J Ethol 36:85-91. doi: 10.1007/s10164-017-0530-z

Polverino G, Cigliano C, Nakayama S, Mehner T (2016) Emergence and development of personality over the ontogeny of fish in absence of environmental stress factors. Behav Ecol Sociobiol 70:2027-2037. doi: 10.1007/s00265-016-2206-Z

R Core Team (2020) R: A language and environment for statistical computing. R Foundation for Statistical Computing, Vienna, Austria. URL: https://www.R-project.org/

Réale D, Reader SM, Sol D, et al (2007) Integrating animal temperament within ecology and evolution. Biol Rev 82:291-318. doi: 10.1111/j.1469-185X.2007.00010.x

Schirmer A, Herde A, Eccard JA, Dammhahn M (2019) Individuals in space: personalitydependent space use, movement and microhabitat use facilitate individual spatial niche specialization. Oecologia 189:647-660. doi: 10.1007/s00442-019-04365-5 
Settele J, Kudrna O, Harpke A, et al (2008) Climatic risk atlas of European butterflies. Pensoft, Sofia-Moscow

Spiegel O, Leu ST, Bull CM, Sih A (2017) What's your move? Movement as a link between personality and spatial dynamics in animal populations. Ecol Lett 20:3-18. doi: 10.1111/ele. 12708

Spiegel O, Leu ST, Sih A, et al (2015) When the going gets tough: behavioural type-dependent space use in the sleepy lizard changes as the season dries. Proc R Soc B Biol Sci 282:20151768. doi: 10.1098/rspb.2015.1768

Stamps JA, Groothuis TGG (2010) Developmental perspectives on personality: implications for ecological and evolutionary studies of individual differences. Philos Trans R Soc B Biol Sci 365:4029-4041. doi: 10.1098/rstb.2010.0218

Stanley CR, Mettke-Hofmann C, Preziosi RF (2017) Personality in the cockroach Diploptera punctata: Evidence for stability across developmental stages despite age effects on boldness. PLoS One 12:e0176564. doi: 10.1371/journal.pone.0176564

Stevens VM, Trochet A, Van Dyck H, et al (2012) How is dispersal integrated in life histories: a quantitative analysis using butterflies. Ecol Lett 15:74-86. doi: 10.1111/j.14610248.2011.01709.x

Stevens VM, Turlure C, Baguette M (2010) A meta-analysis of dispersal in butterflies. Biol Rev 85:625-642. doi: 10.1111/j.1469-185X.2009.00119.x

Stevens VM, Whitmee S, Le Galliard J-F, et al (2014) A comparative analysis of dispersal syndromes in terrestrial and semi-terrestrial animals. Ecol Lett 17:1039-1052. doi: 10.1111/ele. 12303

Svärd L (1985) Paternal investment in a monandrous butterfly, Pararge aegeria. Oikos 45:66- 
455

Takeuchi T (2006) The effect of morphology and physiology on butterfly territoriality. Behaviour 143:393-403. doi: 10.1163/156853906775897879

van de Pol M, Verhulst S (2006) Age-dependent traits: A new statistical model to separate within- and between-individual effects. Am Nat 167:766-773. doi: 10.1086/503331

van de Pol M, Wright J (2009) A simple method for distinguishing within- versus betweensubject effects using mixed models. Anim Behav 77:753-758. doi: 10.1016/j.anbehav.2008.11.006

Van Dyck H (2003) Mate location, a matter of design? Adaptive morphological variation in the speckled wood butterfly. In: Boggs CL, Watt WB, Ehrlich PR (eds) Butterflies: Ecology and Evolution Taking Flight. University of Chicago Press, Chicago, pp 353-366

Van Dyck H, Baguette M (2005) Dispersal behaviour in fragmented landscapes: Routine or special movements? Basic Appl Ecol 6:535-545. doi: 10.1016/j.baae.2005.03.005

Van Dyck H, Matthysen E (1998) Thermoregulatory differences between phenotypes in the speckled wood butterfly: hot perchers and cold patrollers? Oecologia 114:326-334. doi: $10.1007 / \mathrm{s} 004420050454$

Van Dyck H, Matthysen E, Dhondt A (1997) Mate-locating strategies are related to relative body length and wing colour in the speckled wood butterfly Pararge aegeria. Ecol Entomol 22:116-120. doi: 10.1046/j.1365-2311.1997.00041.x

Van Dyck H, van Strien AJ, Maes D, van Swaay CAM (2009) Declines in common, widespread butterflies in a landscape under intense human use. Conserv Biol 23:957-965. doi: $10.1111 / \mathrm{j} .1523-1739.2009 .01175 . x$

Villegas-Ríos D, Réale D, Freitas C, et al (2018) Personalities influence spatial responses to 

2656.12872

479 Wiklund C, Persson A, Wickman P-O (1983) Larval aestivation and direct development as alternative strategies in the speckled wood butterfly, Pararge aegeria, in Sweden. Ecol Entomol 8:233-238. doi: 10.1111/j.1365-2311.1983.tb00503.x

482 Woodgate JL, Makinson JC, Lim KS, et al (2016) Life-long radar tracking of bumblebees. PLoS One 11:e0160333. doi: 10.1371/journal.pone.0160333 
486 Figure 1: Relation between ambient and thoracic temperatures. The dotted line refers to the 487 isothermal condition (1:1 relationship); the solid line represents the regression line based on the 488 model output.

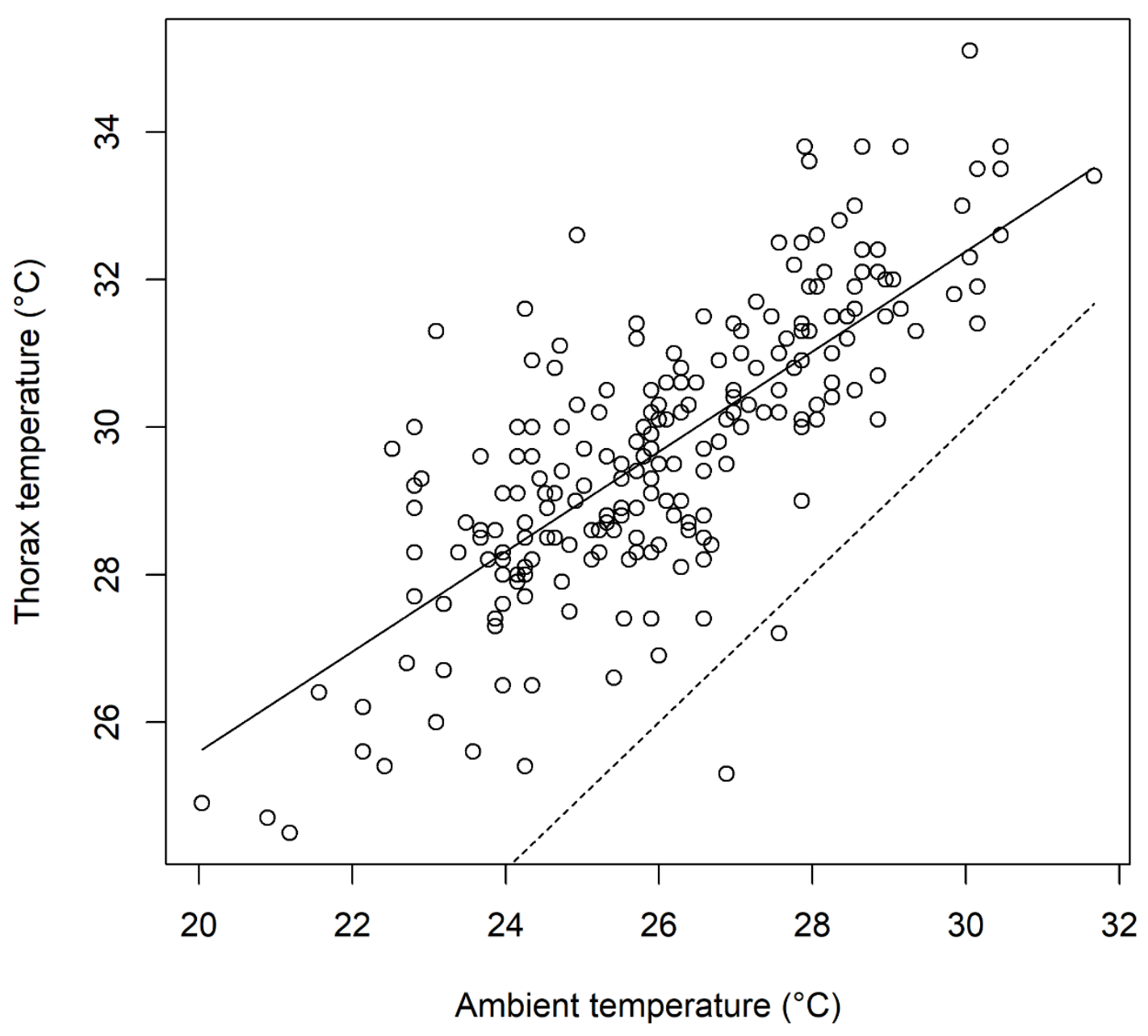

489 
491 Figure 2: Effect of wing wear (used as a proxy for age) on butterfly boldness. We show the 492 predicted values (means and 95\% confidence intervals) based on the model output. Asterisks 493 show significant differences among age classes (after adjustment for multiple comparisons; *P $494<0.05 ; * * \mathrm{P}<0.01)$.

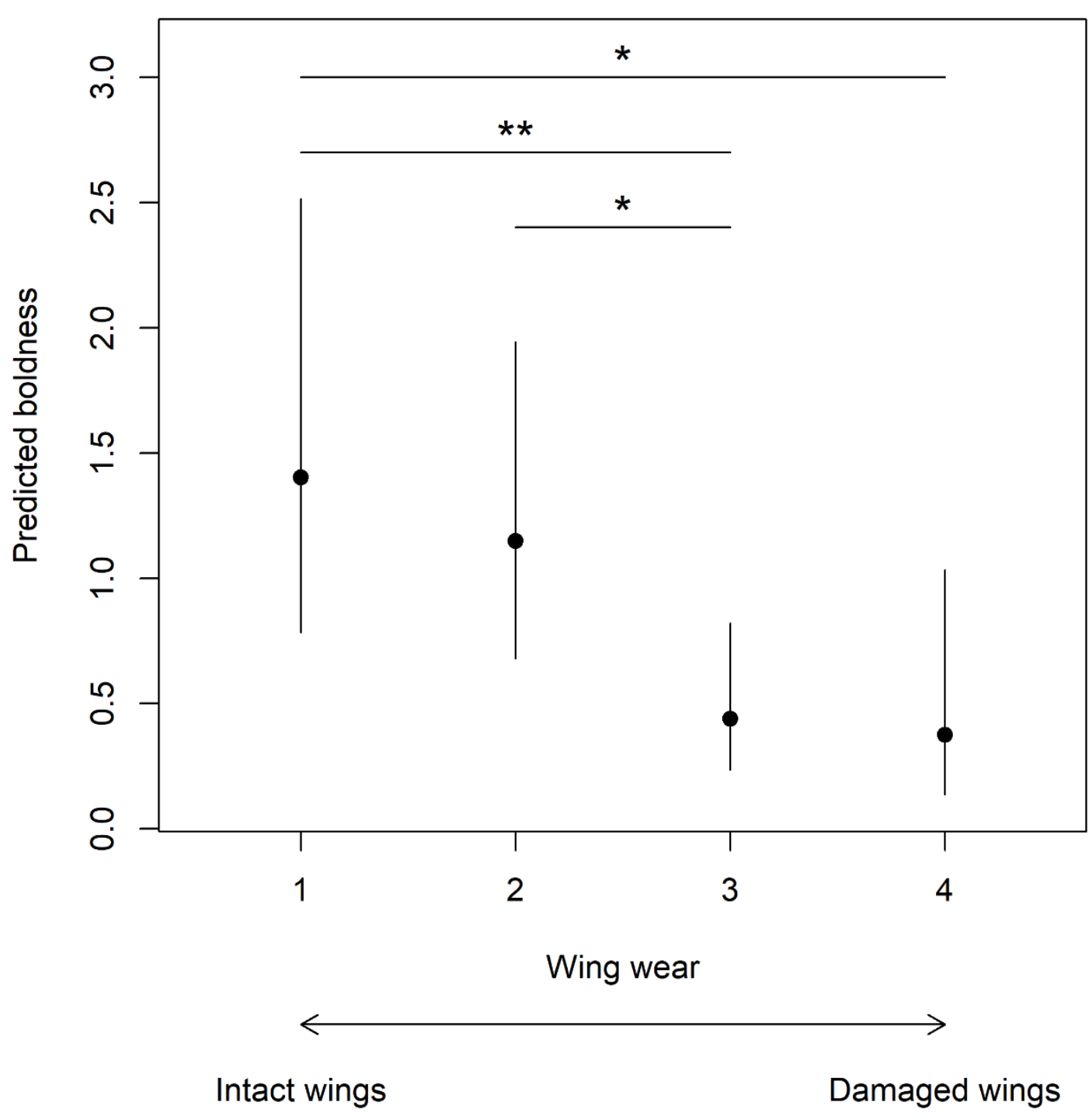


Figure 3: Within-individual change in boldness for recaptured males. The solid line shows the predicted boldness based on the model output; the grey area shows the credible interval.

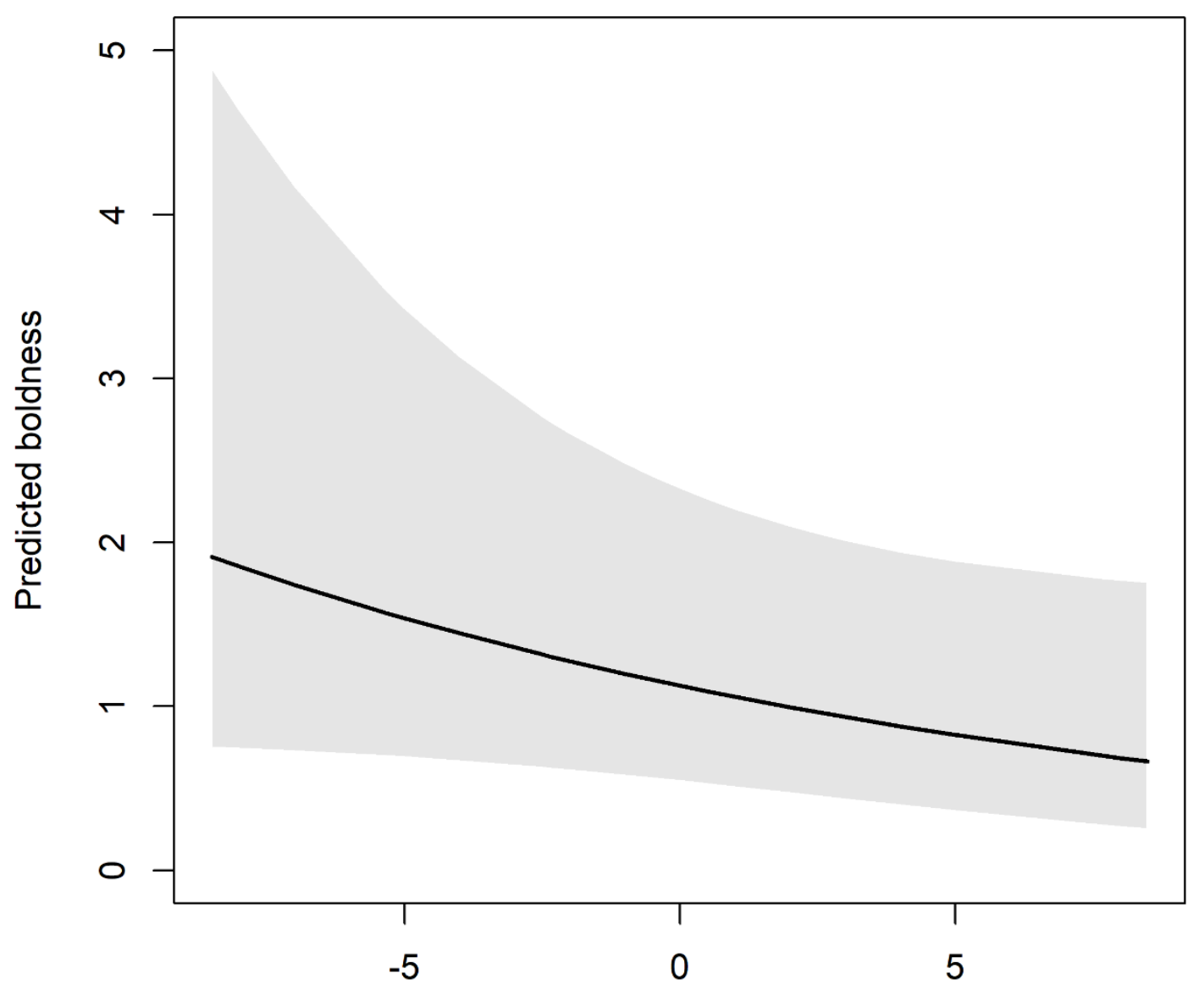

Interval between first and last captures (within-individual centered) 